\title{
Using a cell-based gas biosensor for investigation of adverse effects of acetone vapors in vitro
}

\author{
Ulrich Bohrn ${ }^{\mathrm{a}, \mathrm{b}, c, *}$, Evamaria Stütz ${ }^{\mathrm{a}}$, Maximilian Fleischer ${ }^{\mathrm{a}}$, Michael J. Schöning ${ }^{\mathrm{b}}$, Patrick Wagner ${ }^{\mathrm{c}}$ \\ ${ }^{\text {a } C o r p o r a t e ~ R e s e a r c h ~ \& ~ T e c h n o l o g i e s, ~ S i e m e n s ~ A G, ~ O t t o-H a h n-R i n g ~ 6, ~} 81739$ Munich, Germany \\ ${ }^{\mathrm{b}}$ Institute of Nano- and Biotechnologies (INB), Aachen University of Applied Sciences, Heinrich-Mussmann-Straße 1, 52428 Jülich, Germany \\ ' Institute for Materials Research (IMO/IMOMEC), Hasselt University, Wetenschapspark 1, 3590 Diepenbeek, Belgium
}

\section{A R T I C L E I N F O}

Available online 21 August 2012

Keywords:

Cell-based gas biosensor

Acetone

A549

RPMI 2650

Impedance

Respiration

\begin{abstract}
A B S T R A C T
In this study, a cell-based gas biosensor is presented used for the detection and investigation of gaseous organic compounds in air. The response of living human nasal cells (RPMI 2650) and human lung cells (A549) towards the direct exposure of gaseous substances for $10 \mathrm{~min}$ is monitored with a multiparametric sensor system. Changes in the cellular impedance, oxygen consumption rate and acidification rate can be recorded after the exposure and represent the cytotoxicity of the present gas. The sensor is able to notify the presence of acetone in aqueous solution (2\%) but in notably lower concentrations in the gas phase (100-333 ppm) within 30-60 min after the end of the gas exposure. Cell viability is not affected by a sequential exposure to humidified synthetic air (60\% r.h.) with a flow rate of $300 \mathrm{ml} / \mathrm{min}$ and therefore offers the possibility for a continuous air monitoring. In addition, exposure to synthetic air has no influence on the signals of consecutive acetone exposure. The system might be used in the future for the monitoring of ambient air in work spaces.
\end{abstract}

(c) 2012 Elsevier B.V. All rights reserved.

\section{Introduction}

Indoor air has important and wide ranging effects on human health and work efficiency, due to the fact that humans are permanently inhaling a complex mixture containing numerous different pollutants (Persoz et al. 2011). The majority of these indoor air pollutants are classified as volatile organic compounds (VOC). VOC is a denomination used for a wide group of organic compounds whose vapor pressure is at least $0.01 \mathrm{kPa}$ at $20^{\circ} \mathrm{C}$ (VOC Solvents Emissions Directive, (1999)). Acetone, a colorless and highly volatile liquid is one type of VOC agent (TLV, $500 \mathrm{ppm}$ ) (ACGIH, 1999; Costa et al., 2006). Acetone is frequently and quantitatively represented in the composition of coatings, paints, adhesives and cleaning materials (Arts et al., 2002; Costa et al., 2006). It is well known that due to the lipophilicity and the low molecular weight, acetone vapors can readily cross and penetrate deeply through epidermal layers, thus enhancing dissolution of lipid matrix (Tsai et al. 2001). After inhalation, acetone is absorbed by the respiratory tract and distributed to all tissues but rapidly cleared from the body by liver metabolism and excretion. Acute acetone exposure leads to reported symptoms

\footnotetext{
* Corresponding author at: Corporate Research \& Technologies, Siemens AG, Otto-Hahn-Ring 6, 81739 Munich, Germany. Tel.: + 4989636 43592; fax: +498963646881 .

E-mail addresses: ulrichbohrn@hotmail.com, ulrich.bohrn.ext@siemens.com (U. Bohrn).
}

like unconsciousness, headache, and irritation of nose and throat in human. Beside the exogenous uptake, acetone is formed endogenously in the mammalian body from fatty acid oxidation and is of a low order of acute inhalation toxicity (4-h LC50 in rats: 32,000 ppm) (Arts et al., 2002).

For toxicological investigation of gases, in vitro setups for the direct exposure of cells in rolling bottles (Bolton et al., 1982) or rocking platforms (Guerrero et al., 1979) were developed in the past. Today, exposure of cells at the air-liquid-interface is state of the art (Aufderheide and Mohr, 1999, 2000; Knebel et al., 1998). In this approach, cells are cultured on permeable membranes directly at the air-liquid-interface. From the top, cells are exposed to airborne contaminants starting from gases (Ritter et al., 2001) including VOCs (Aufderheide, 2008) and complex mixtures like cigarette smoke (Röker et al., 2010; Wolz et al., 2002) and therapeutic aerosols (Deschl et al., 2011). Unfortunately, this system is not suitable for a constant monitoring as the cellular alteration, caused by the gas, has to be evaluated with cellular endpoint assays like MTT (Mosmann, 1983) or LDH (Sasaki et al., 1992).

Cell-based sensors using are used since several years for the monitoring of cytotoxic events (Abdelghani et al., 2002; Hillebrandt et al., 2001). In this study, the 2500 Analyzing System (Bionas ${ }^{\circledR}$, Rostock, Germany) was used for the monitoring of the impact of acetone on cells. This multi-parametric sensor device was already used in applications for water monitoring (Kubisch et al., 2012). The first results of an adapted system for the 
monitoring of highly toxic gases like carbon monoxide and ammonia (Bohrn et al. 2011a and b) have been published recently. The system is equipped with a T-shaped gas exposure device to enable the direct contact of the gas phase with the cell membrane. Therefore, liquid nutrient medium covering the adherent mammalian cells on the sensor chip has to be removed to avoid this liquid barrier.

The aim of this study was to manage successive exposures of living mammalian cells to a non-acute toxic VOC (acetone). The chosen cell lines are representatives of VOC's target tissues which were exposed in an airlifted interface. Several cell culture conditions before and during the exposure were optimized to achieve conditions for the exposure which decrease mechanical effects that could lead to cell damage. Achieved results of the gas exposure measurements were compared with cells treated with liquid acetone regarding their sensitivity. In addition, standard cell biology assays were conducted to evaluate the vitality and membrane integrity of the exposed cells.

\section{Materials and methods}

\subsection{Chemicals and reagents}

Dulbecco's Modified Eagle Medium (DMEM) and Modified Eagle Medium (MEM) were purchased at Gibco (Darmstadt, Germany). Heat inactivated fetal bovine serum (FBS), phosphate buffered saline (PBS) and trypsin $0.05 \% /$ EDTA $0.02 \%$ were purchased at Biochrom (Berlin, Germany). Fibronectin and Triton X-100 were purchased at Sigma-Aldrich (Steinheim, Germany). Penicillin, streptomycin and Hepes were purchased at BioWhittaker (Heidelberg, Germany). Liquid acetone was purchased at VWR (Fontenay-sous-Bois, France). Acetone gas was purchased in 99.999\% purity from Linde (Munich, Germany).

\subsection{Cell line, culture conditions and cell exposures}

This work includes experiments with the human alveolar epithelial cells, A549 and the human nasal cells RPMI 2650 (DSMZ, Braunschweig, Germany). DMEM supplemented with $10 \% \mathrm{FBS}, 100$ units $/ \mathrm{ml}$ penicillin and $100 \mu \mathrm{g} / \mathrm{ml}$ streptomycin was used to grow the cells in cell culture flasks in a humidified incubator $\left(5 \% \mathrm{CO}_{2}, 37^{\circ} \mathrm{C}\right)$. The cell line was used within 20 passages from the received stock for all experiments. Grown cells were enzymatically harvested in the incubator within 5 min using trypsin $0.05 \% /$ EDTA $0.02 \%$ and suspended in DMEM. Suspended cells were seeded on Metabolic Chips SC 1000 (Bionas, Rostock, Germany). Prior to the seeding, the sensor chips were soaked with EtOH (70\%) and rinsed with $\mathrm{Ca}^{2+}$ - and $\mathrm{Mg}^{2+}$-free PBS. The seeding density was 200,000 cells/chip RPMI 2650 and 150,000 cells/chip A549 (chip surface area $=0.7088 \mathrm{~cm}^{2}$ ). The cells were left to adhere until $100 \%$ confluency. Control cells introduced at each experiment correspond to cells cultured in submerged conditions without any exposure.

For the measurement of the effects of acetone on the living cells, the Bionas 2500 analyzing system was used as described previously (Bohrn et al. 2011b). Sensor chips with a confluent cell monolayer were placed inside the 6 chip ports (so called biomodules) of the 2500 analyzing system. The RM was pumped via an autosampler to the biomodules containing the sensor chips. The flow rate was adjusted to $56 \mu \mathrm{l} / \mathrm{min}$. A perfusion head enables the liquid exchange and the connection of the liquid on the sensor surface with a $\mathrm{Ag} / \mathrm{AgCl}$ reference electrode. Each of the 6 sensor chips monitors 3 cell parameters in parallel: the cell morphology via an interdigitated impedance electrode, the cellular oxygen consumption rate (respiration) via 2 Clark-type electrodes, and the cellular acidification (metabolic activity) via $5 \mathrm{pH}$-sensitive field-effect transistor electrodes (Baumann et al. 1999; Ehret et al. 1997). Stop/go intervals of $3 \mathrm{~min}$ each were chosen to enable the complete removal of medium during the go phase. A stop phase of $3 \mathrm{~min}$ is sufficient to calculate reliably the slope of the acidification and the respiration rate. In total, 1 data point per stop/go cycle is calculated and plotted in the normalized diagram (acidification rate and respiration rate, respectively, were recorded during the stop phase; 1 data point $/ 6 \mathrm{~min}$ ). The data were normalized to a $100 \%$ value $1 \mathrm{~h}$ prior to the exposure phase to simplify the comparison of the untreated and the exposed cell sensor chips. After a time period of $3 \mathrm{~h}$ with untreated running medium (RM; carbonate buffer free DMEM supplemented with $1 \%$ Hepes and 1\% FBS, pH 7.4), acetone solved in RM was added for another $3 \mathrm{~h}$. Acetone solutions were prepared by diluting the appropriate amount in RM. The $\mathrm{pH}$ value of the $\mathrm{RM}$ was not influenced by the addition of acetone ( $\mathrm{pH} 7.36$ at 5\% acetone). For sequential exposure measurements, recovery phases with RM $(3 \mathrm{~h})$ alternate with acetone solution phases $(3 \mathrm{~h})$ for 8 times.

The experiments were terminated by addition of $0.2 \%$ Triton $\mathrm{X}-100$ containing $\mathrm{RM}$ for another $2 \mathrm{~h}$ leading to immediate disruption of the cellular lipid bilayer membrane. The data recorded at this phase represent a cell free sensor surface state. Before and after each experiment, the whole fluidic system was cleaned and disinfected with $70 \%$ ethanol and $\mathrm{H}_{2} \mathrm{O}$.

\subsection{Gas exposure device and Gas exposure measurements}

The gas exposure measurement procedure differs from the measurements of solved acetone and were performed as described previously in detail (Bohrn et al. 2011a). The metabolic sensor chips, covered with a confluent cell monolayer and $200 \mu \mathrm{l}$ $\mathrm{RM}$, are inserted in the biomodules of the 2500 analyzing system and connected to the reference electrode and the pumping system via the perfusion head. RM is pumped over the cells in an alternating $3 \mathrm{~min}$ stop/go cycle. Immediately before the gas exposure, pumps were stopped to prevent further transport of the liquid medium to the cells. For exposure of the cells on the sensor surface with gaseous acetone, the nutrient medium above the cells is removed with a peristaltic pump $(5-10 \mathrm{sec})$ to enable a direct contact of the gas phase with the cell membrane for $10 \mathrm{~min}$. Residues of liquid medium have to be avoided strictly as this forms a liquid barrier layer which protects the cells from the acetone vapor. The gas is transported from a gas mixing station to the sensor chip. Synthetic air $\left(\mathrm{N}_{2}: \mathrm{O}_{2} / 80: 20\right)$ is used as a carrier gas for the acetone. Acetone gas is diluted in synthetic air to achieve the desired concentrations of $100 \mathrm{ppm}$ and $333 \mathrm{ppm}$. In addition, the synthetic air is humidified up to $60 \%$ relative humidity (r.h.) via a heated water bubbler. The gas flow was controlled by mass flow controllers and adjusted to $300 \mathrm{ml} / \mathrm{min}$. A T-shaped gas exposure device was plugged on the culture vessel of the sensor chip (Fig. 1) which guides the gas stream over the cells to get it in contact with the cellular membrane via diffusion. Former studies (Bohrn et al. 2010, 2011a) demonstrated that exposure durations of $10-15 \mathrm{~min}$ are sufficient to generate detectable changes in the cellular signals, while the cells still rest on the sensor surface without being mechanically detached. For all experiments, reference measurements have to be done to compare the effects of the acetone gas with the influence of non-irritant humidified synthetic air. During the gas exposure, there is no connection to the reference electrode in the perfusion head and therefore, no real-time is possible for the acidification and respiration measurements. Immediately after the gas exposure, $200 \mu \mathrm{l}$ of prewarmed $\mathrm{RM}\left(37^{\circ} \mathrm{C}\right)$ was gently added to the cells on the chip and the perfusion head is placed back inside the sensor chip vessel to reconnect the reference electrode and the 


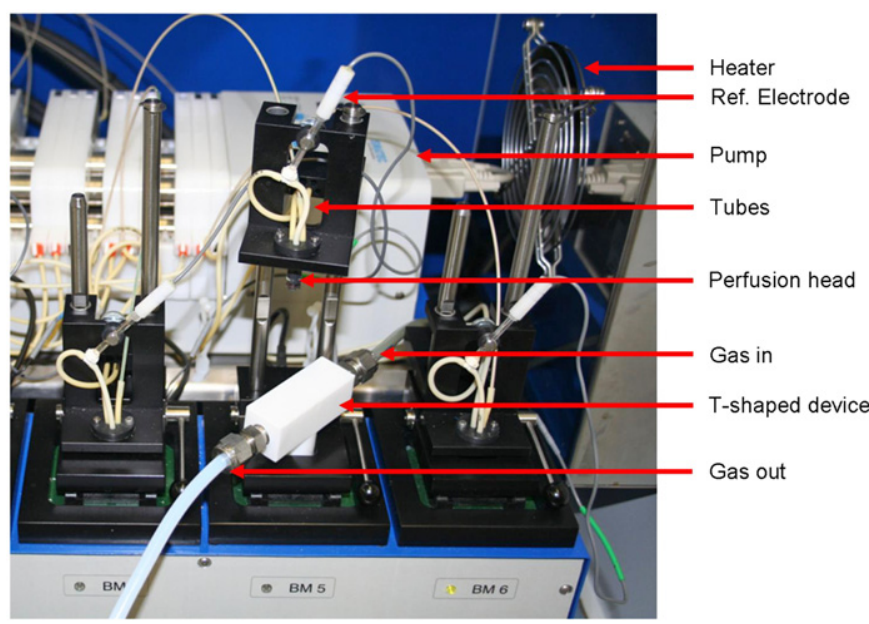

Fig. 1. Sensing unit of a Bionas 2500 Analyzing System equipped with a T-shaped gas exposure device on a metabolic sensor chip. The perfusion head, which is connected to the nutrient medium delivering pumping system in the back and the reference electrode, is lifted during the direct gas exposure.

pumping system. The closed perfusion head establishes the connection to the reference electrode, which enable again the measurement of acidification and oxygen consumption. The pumping system was started again to supply the cells with nutrient medium and to achieve data generation with the previously described stop/go modus. The experiment was conducted with RM for at least $2 \mathrm{~h}$ in addition until the measurement was stopped. For sequential exposure measurements, the same procedure was repeated after $1 \mathrm{~h}$ of cell recovery in the RM. In parallel, a control cell sensor chip was continuously supplied with RM without gas exposure. Control air exposure measurements were done by exposing the cells on the chip with clean, humidified synthetic air (0\% acetone; $60 \%$ r.h.). As the minimum requirement for acceptable control samples (synthetic air exposure), culture conditions allowing a survival above $90 \%$ compared to the untreated control (no gas exposure) were considered as was done of other groups before (Pariselli et al. 2009). This was achieved for both A549 cell line and RPMI 2650 cell line.

\subsection{Biological activity assessment}

\subsubsection{Cell viability—LDH assay}

Membrane integrity was determined by measuring the release of intracellular lactate dehydrogenase (LDH) into the supernatant medium. LDH was measured using an in vitro assay kit in which LDH oxidizes the substrate L-lactate buffered at a $\mathrm{pH}$ of 9.4 in the presence of $\mathrm{NAD}^{+}$to yield pyruvate and $\mathrm{NADH}, \mathrm{H}^{+}$which absorbs light at $340 \mathrm{~nm}$. Concentrations were initially expressed as unity of consumed substrate per liter and cellular viability, expressed as a percentage, was calculated with sample concentration and maximal LDH activity (positive control obtained by cell lysis after $2 \mathrm{~h}$ treatment with $1 \%$ Triton X-100), each normalized on control cells concentration $(n=3)$.

\subsubsection{Cell proliferation-MTT assay}

Cell viability after exposure to organic solvents was assessed by measuring reduction of the tetrazolium dye MTT (3-(4, 5-dimethylthiazol-2-yl)-2,5-diphenyltetrazolium bromide) by mitochondrial succinate dehydrogenase following the method optimized by Mosmann (1983). Cells were exposed to $100 \mu \mathrm{L}$ acetone solved in DMEM for $24 \mathrm{~h}$. Afterwards, $10 \mu \mathrm{L}$ MTT $(0.5 \mathrm{mg} / \mathrm{ml}$ final concentration) was added to each well and incubated for $4 \mathrm{~h}$ at
$37{ }^{\circ} \mathrm{C}$ (humidified atmosphere). Solubilization solution (isopropanol with $5 \%$ Triton X-100) was incubated with the cells over night (16 h) to allow solubilization of formazan crystals. Absorbance at $570 \mathrm{~nm}$ was measured and results were expressed as percentage of nontreated cells.

\section{Results and discussion}

\subsection{Cell viability assay (LDH- and MTT-assay)}

The human lung cell line A549 is a heavy used lung model cell line which is described to share several fundamental characteristics with human lung alveolar type II cells (Hukkanan et al. 2000). The special usability of this cell line for gas exposure experiments was demonstrated recently, as A549 cells hardly react towards humidified synthetic air but show reasonable response towards direct exposure of mainstream and filtered cigarette smoke (Röker et al. 2010) as well as diesel exhausts (Röker et al., 2010; Tsukue et al., 2010) and volatile compounds like formaldehyde, benzene and toluene for up to $3 \mathrm{~h}$ (Aufderheide, 2008; Bakand et al., 2005; Knebel et al., 1998). It was reported that the response profile of interleukin 6 and interleukin 8 expression of A549 cells was not altered by the air exposure for $6 \mathrm{~h}$ (Bitterle et al., 2006). Also the glutathion redox status of the cell is not changed by the exposure to synthetic air (Pariselli et al., 2009). DNA damage of A549 cells exposed to clean air for $1 \mathrm{~h}$ have been reported to be less than $10 \%$ (Gminski et al., 2010). MTS and NRU assays, performed after $120 \mathrm{~min}$ exposure to synthetic air show almost no alteration in their results (Bakand et al., 2006). The human nasal cell line RPMI 2650 was chosen for the experiments as it is known from literature, that these cells are valuable model cell lines for nasal exposure as they reach full confluency on polymer membranes when they are grown at the air-liquid-interface (Bai et al., 2008; Wengst and Reichl, 2010). This indicates that the cells are resistive against the longer exposition to air. Cells are grown on the surface of fibronectin coated metabolic sensor chips and form a confluent cell monolayer within $16-24 \mathrm{~h}$.

The $24 \mathrm{~h}$ exposure of RPMI 2650 cells towards increasing concentrations of solvent acetone determined decreasing cell viability in terms of membrane integrity (Fig. 2a) and mitochondrial reducing activity (Fig. $2 b$ ). The toxic effect of acetone starts at concentrations of $1-2 \%$. This is in good accordance to results of MTT assay of acetone exposed human skin (Costa et al., 2006). In this study, damage of skin after acetone exposure was detected at concentrations of $10^{5} \mathrm{ppm}$ acetone and more.

\subsection{Effects on RPMI 2650 cells and A549 cells after exposure to acetone in liquid medium}

The response of RPMI 2650 and A549 cells towards liquid acetone as a model substance for an organic compound was investigated. The time-transients of impedance, respiration and acidification measurements of acetone exposed RPMI 2650 cells are shown in Fig. 3a-c. Acetone solved in water based nutrient medium caused signal changes relative to the control measurements at concentrations of $2 \%$. For RPMI 2650 cells, the impedance values are reduced in a concentration dependant manner (Fig. 3a). This is in good accordance to the literature as acetone is highly lipophilic and therefore used in industry as a solvent. Acetone exposure leads to an increase in the respiration rate and in the acidification rate of RPMI 2650 cells (Fig. 3b and c) can be recovered instead of the impaired impedance which hardly recovers after acetone treatment. Fig. $3 d$ and e show the averaged values of 3 independent measurements after the exposure of 

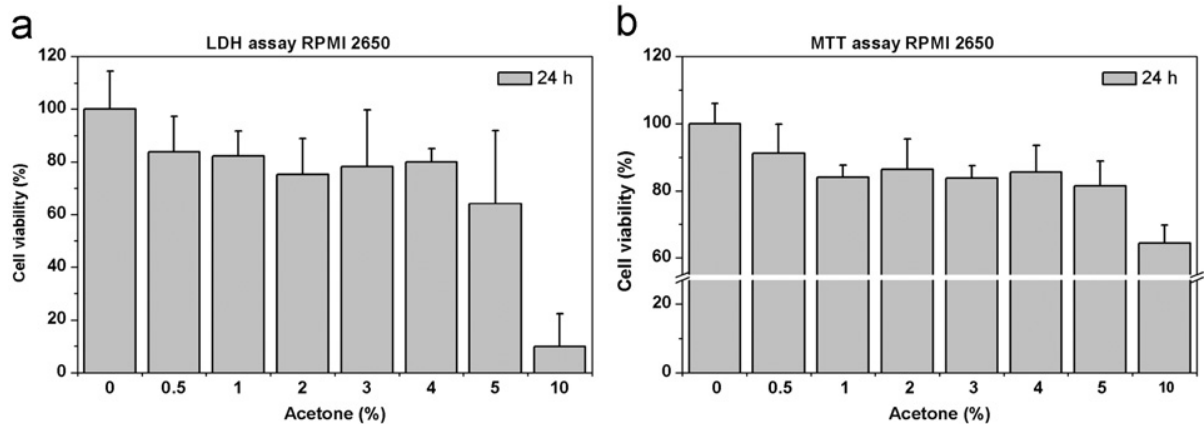

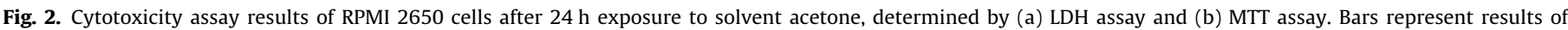
control ( $0 \%$ acetone) and increasing doses of acetone. Mean \pm SD viability (\% of controls, $n=3$ ).
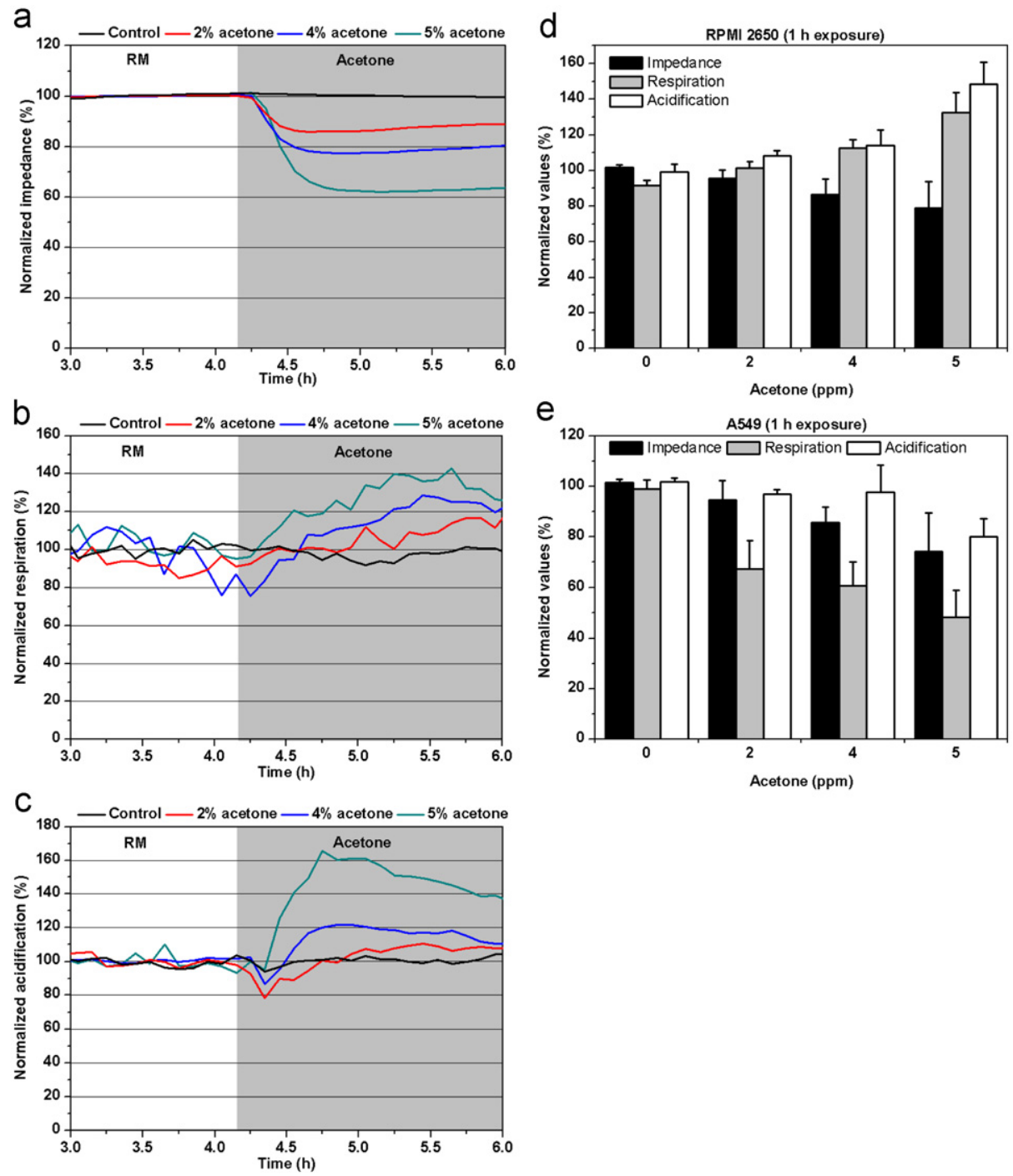

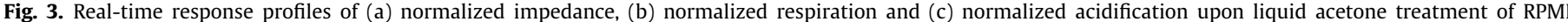
2650 cells. Mean \pm SD impedance, respiration and acidification values of (d) RPMI 2650 and (e) A549 cells after treatment with liquid acetone for 1 h ( $n=3$ ).

RPMI 2650 cells (Fig. 3d) and A549 cells (Fig. 3e) for $1 \mathrm{~h}$ with various acetone concentrations. The response pattern of the A549 cells differs from the RPMI 2650 cells as the respiration rates are reduced in a dose-dependent manner with increasing acetone concentrations. In addition, the acidification rates of A549 cells are also decreasing with increased acetone concentrations, in contrast to the acidification rates of the RPMI 2650 cells, which show a strong increase in the acidification rate (Fig. 3d). Differences in the response pattern of different cell lines might be the associated with the individual metabolic behavior of these cells. This has to be kept in mind if a specific cell line is chosen for an application in monitoring pollutants. The effects that are observed with the monitored parameters of the sensors system are always relative effects, which have to be compared to the 
control measurement. The achieved results are in the range of standard cell culture cytotoxicity assays like the MTT assay and the LDH assay. Both assay formats detect cytotoxic effects of acetone at concentrations of about $2 \%$. The sensor system is therefore a comparable and equivalent system for the investigations of the toxicity of dissolved solvents.

\subsection{Effect on A549 cells after sequential exposure acetone in liquid medium}

In a separate experiment A549 human lung cells were exposed to liquid acetone sequentially for 8 times. After an adaption phase of approximately $4 \mathrm{~h}$, cells were sequentially exposed for $3 \mathrm{~h}$ to acetone containing RM ( $2 \%$ and $4 \%$ acetone) and acetone free RM (Fig. 4a-c). For the first acetone exposure phase, the cells responded in accordance to the results displayed in (Fig. 3e) which means a decrease to roughly $70 \%$ of control for the respiration (Fig. 4b), as well as a decrease to $80-90 \%$ of the impedance and acidification (Fig. 4a and c). During the following $3 \mathrm{~h}$ RM exposure, the impedance almost reached the value of the untreated control measurement, which was set as a $100 \%$ reference (Fig. 4a). Following exposure phases decreased the impedance values of the acetone exposed cells even more. The intermitting recovery phase of $3 \mathrm{~h}$ was not sufficient anymore to reach the control values. After 5 exposure phases, the impedance values reached a level of $80 \%$ of control for $4 \%$ acetone solutions and $85 \%$ for $2 \%$ acetone solution. Further exposure phases did not enlarged the adverse effect on the impedance as the values for both tested acetone concentrations increased, although a full recovery was not available at all. Acetone seems to have only minor cumulative effect on the cell membrane stability and integrity of the A549 cells when they are treated with subtoxic acetone concentrations $2-4 \%$. The achieved values are in accordance with the results obtained with the MTT assay and show the good reproducibility of the performed cell-based sensors assay.

A different response pattern was observed for the effects on the cellular oxygen consumption rates. After the first acetone exposure, which lead to a respiration decrease down to $60 \%$ of the control values, the respiration increased dramatically at the beginning of the recovery phase (Fig. 4b) which might be an artifact due to the alterations in the medium constitution during the change from acetone-containing medium to acetone-free RM. However, after $3 \mathrm{~h}$ of recovery, the respiration rates for both acetone concentrations reached almost $100 \%$ of control. During the following acetone exposures, the respiration was always decrease to not more that $60 \%$ of control despite some artifacts at the beginning of the exposure phases $6-8$. The ability to recover for the acetone induced stress decreased continuously as the cells reached only $70-80 \%$ of the control after 8 exposure cycles. Therefore, it can be stated, that the effects on the oxygen consumption of the A549 cells is cumulative over the time.

In contrast, the cellular metabolic activity behaves similar to the changes in the impedance values. With an increasing number of acetone exposure cycles, the acidification rate during the exposure decreases as well as the ability to recover during the phase of RM without acetone. After 5 exposure cycles, this trend is stopped and even inverted as the acidification rates increase in the exposure phases 6-8 compared to exposure phase 5 . This effect might occur due to an adaption of the cells to the acetone containing medium. Another reason might be a relatively activated metabolism of the cell to gain more energy via glycolytic activity as the oxygen dependent energy producing pathways are more and more disturbed.

The obtained results demonstrated the strength of the presented multiparametric system as the extent of the response of
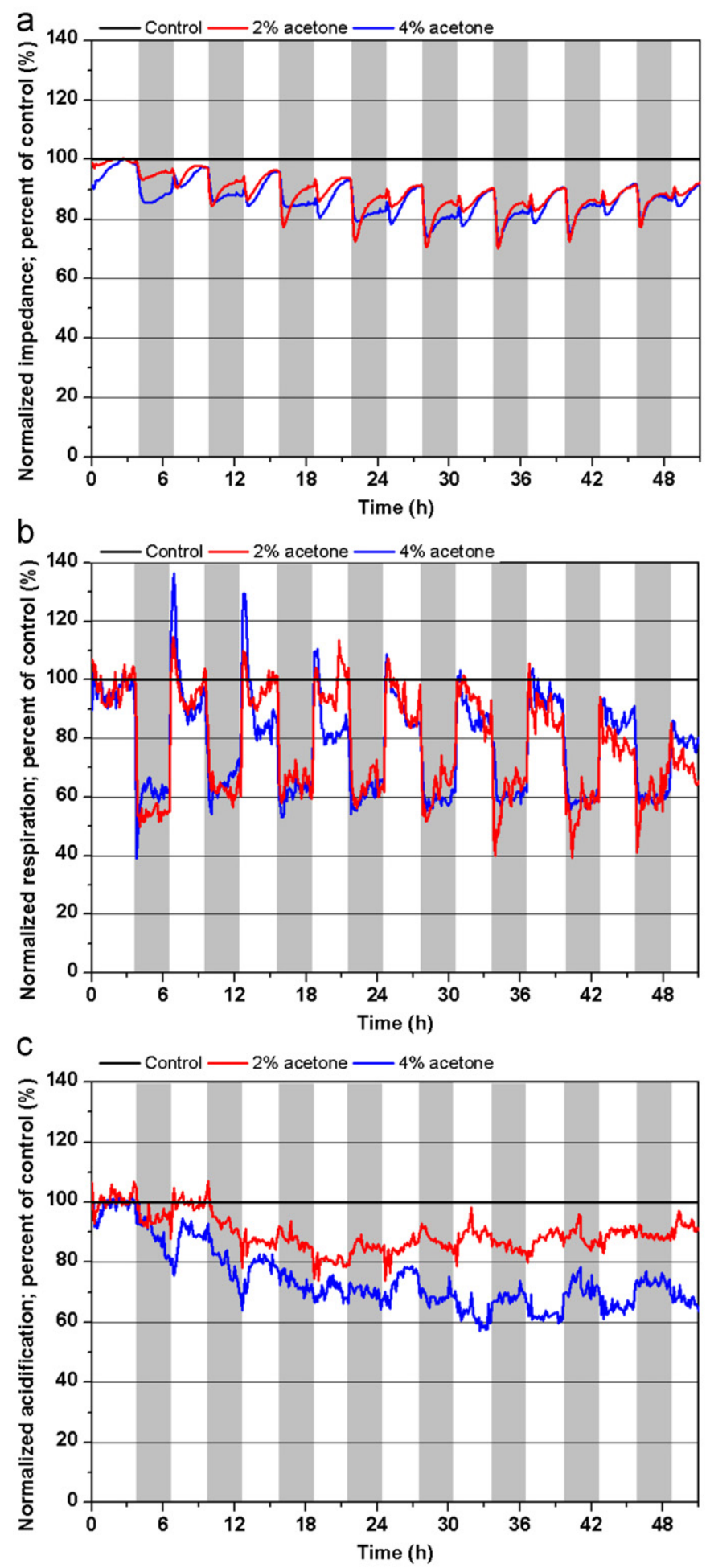

Fig. 4. Real-time response profiles of (a) normalized impedance, (b) normalized respiration and (c) normalized acidification upon sequential exposure of A549 cells to acetone (gray background) diluted in liquid running medium (white background).

the cells towards acetone differs according to the monitored type of sensor. Impedance-only sensor systems might show only low response and a precise evaluation of the toxic effects of the solution can't be given without additional physiological sensors. Compared to standard cytotoxicity assays, the cells in the cellbased sensor can be exposed for several times while recording the 
changes in the monitored parameters in real-time as the cells are not harmed by the measurement method.

\subsection{Effects on RPMI 2650 cells after exposure to acetone vapor}

Direct exposure of nasal cells to gaseous acetone causes changes in all 3 monitored cell parameters (Fig. 5). Changes occur at acetone concentrations in the range of several hundred ppm and are therefore much lower than the concentrations needed when acetone is applied as liquid in nutrient medium (see 3.2). The direct exposure on the cellular membrane seems to have a much higher impact as acetone is able to dissolve hydrophobic molecule species like phospholipids out of the membrane. The results in (Fig. 5a) show a concentration dependent decrease of the impedance values after an exposure to gaseous acetone for $10 \mathrm{~min}$, whereas synthetic air has almost no damaging effect on the cell layer integrity. The immediate increase of the respiratory activity after the end of the gas exposure (Fig. 5b) recovers over the following treatment with
RM which indicates that no permanent change in the respiration system has been caused. An increase in the acidification rates of the nasal cells is observed too (Fig. 5c), although the increase in the cellular metabolism is smaller compared with the respiration. The used gas exposure parameters (60\% r.h.; $300 \mathrm{ml} / \mathrm{min}$ flow rate; 10 min exposure time) are chosen to establish control measurements with synthetic air which keeps the cellular response after the exposure almost undisturbed compared to the values prior to the gas exposure. This simplifies the comparison with the test gases and ensures that no cell damage occurs because of the exposure conditions themselves. The chips were checked microscopically after the exposure to synthetic air and no damages in the cell layer were observable. The results of the monitored parameters $1 \mathrm{~h}$ after the end of the gas exposure are summarized in (Fig. 5d).

Interestingly, the response pattern of the A549 cells towards acetone vapor differs from the results obtained with liquid acetone solved in nutrition medium (Fig. 5e). After an exposure to acetone gas, acidification as well as respiration rates are increased (Fig. 5e) with increasing amount of acetone vapor. This is in contrast to the
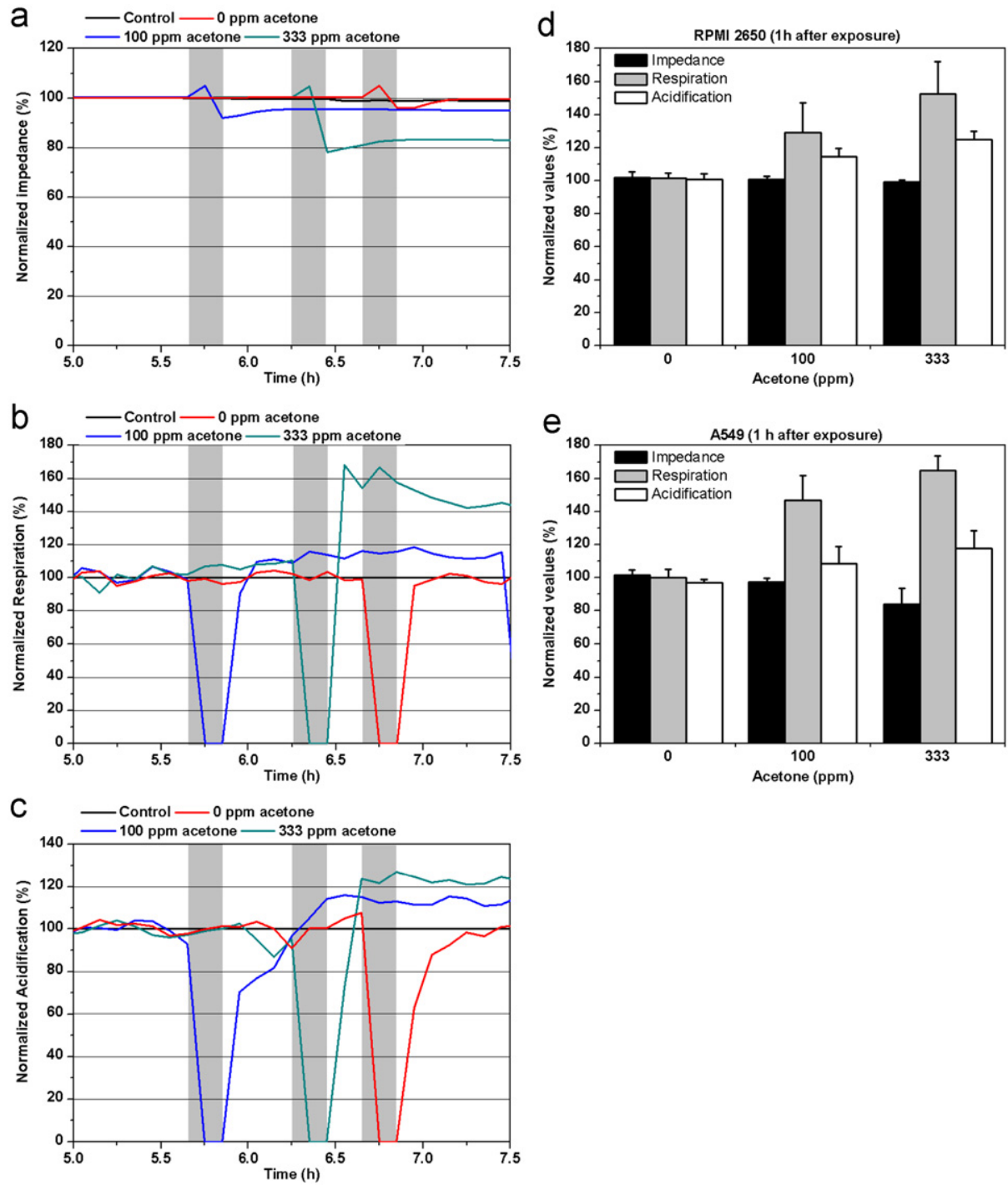

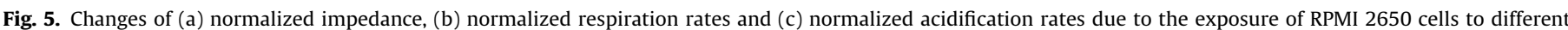

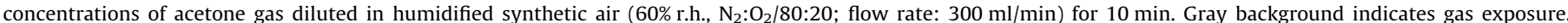

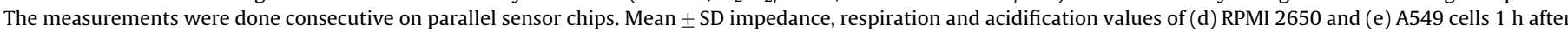

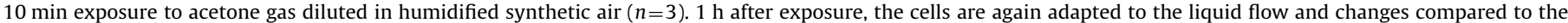
control measurement are caused by the acetone. 
results of A549 cell exposed to liquid acetone, where a decrease of the acidification and the respiration rate is observable with increasing acetone amounts. (Fig. 3e). The exposure of A549 cells to acetone in liquid phase seems to influence different biochemical mechanism compared to those, which are altered at the direct and undisturbed contact with the gas phase. As mentioned above, differences in the metabolic profile of the investigated cell lines might cause the differences in the response towards the gaseous acetone. The impedance values decrease with increasing acetone gas concentration, which is in accordance to the results obtained with liquid acetone (Fig. 3e).

The remarkably lower concentration of detected acetone vapors display the benefit of the direct air exposure towards the use of acetone solutions. With the gas exposure set up, concentrations in the range of the threshold limit values are detectable which is around two magnitudes lower. The direct exposure method is applicable also for which are not or only hardly soluble in water based liquid medium and therefore extends the range of potential detectable VOCs.

\subsection{Effect on A549 cells after sequential exposure to synthetic air and acetone vapor}

The third and last issue dealt with the feasibility of the cellbased sensor system to sequential gas exposure. This is an essential precondition for the use of such a sensor system for the continuous monitoring of air samples. To validate sequential exposure, cellular effects of repeated exposure of A549 cells towards humidified synthetic air were investigated (Fig. 6a). Synthetic air is supposed to cause no or an only minor change in the cellular parameters as no pollutant is present. The main task is to keep the cells alive as they have to stand shear forces due to the gas flow and to avoid extended drying by humidifying the synthetic air. At the end of the experiment, no decrease in viability was observed when cells were exposed 1-4 times to synthetic air. The 4 times exposure to synthetic air did not impact the physiological parameters respiration and acidification (Fig. 6a) which leads to the assumption, that the cells on the sensor surface are able to keep their physiological system stable even after multiple stress events. The results indicate that cells response almost in the same way towards $1-4$ synthetic air exposures which makes them feasible for long term exposure studies.

A549 cells were next exposed, first to synthetic air (SA) and then to acetone (Ac) (Fig. 6b). The initial exposure to synthetic air showed no altering effect at the chosen parameters (60\% r.h., $300 \mathrm{ml} / \mathrm{min}$ ). After a recovery phase of $90 \mathrm{~min}$, the same cells were exposed to $100 \mathrm{ppm}$ acetone. The increase in the respiration and the acidification was comparable to the results achieved for only single time exposed A549 cells (Fig. 5e). The prior exposure to synthetic air did not alter the signal pattern of the acetone exposure curves.

Results concerning the metabolic parameters respiration and acidification for the initial acetone exposure $(100 \mathrm{ppm})$ showed an increase comparable to the results shown in (Fig. 5d, Fig. 6c). The initially increased respiration decreases again during the recovery phase of 90 min between the 2 exposures, while the increased acidification rates keeps constant signals. The following exposure to synthetic air did not influence the trend of the respiration and acidification rates of the previously acetone exposed cells. Humidified synthetic air seems to have no harmful effects even for the pre-stressed cells.

Taking these results together, that is sequential exposure to synthetic air with or without acetone gas (SA-SA, SA-Ac and Ac-SA), it could be confirmed that multiple as well as a prior or following synthetic air exposures have no influencing effects on
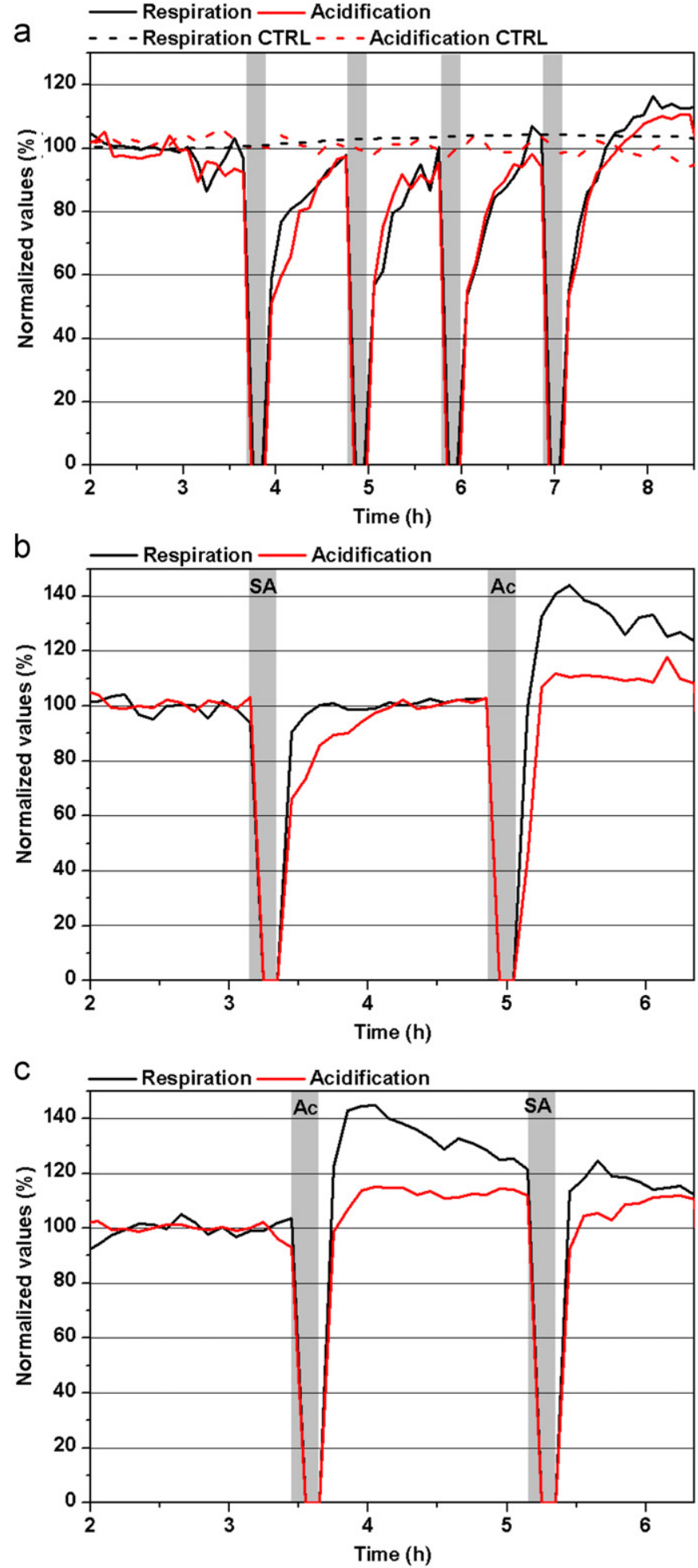

Fig. 6. Response of A549 cells to sequential exposure with (a) $4 x$ synthetic air (SA; dashed lines represent untreated control cells). (b) Exposure of A549 cells with synthetic air followed by acetone (Ac) and (c) acetone followed by synthetic air. $90 \mathrm{~min}$ recovery phase between the gas exposures. Gray background indicates gas exposure (exposure duration: $10 \mathrm{~min}$; acetone concentration: $100 \mathrm{ppm}$; $60 \%$ r.h.; flow rate: $300 \mathrm{ml} / \mathrm{min})$.

A549 physiology. A recovery phase between the gas exposures is necessary to supply the cells with nutrient medium. This opens the possibility to use the system for the monitoring of ambient air as this environment is in general not polluted and therefore 
should not affect the cellular parameters until an increased pollutant concentration is present.

\section{Conclusion}

The use of living mammalian cells grown on sensor electrodes for the detection of toxic gases is an emerging approach. Human alveolar cells (A549) and human nasal cells (RPMI 2650) on a silicon sensor chip were exposed to dissolved acetone and acetone vapor using a gas exposure device. The cellular morphology, respiration rate and acidification rate are monitored in real-time. Direct exposed cells react towards acetone vapor at lower concentrations (100-333 ppm) than towards dissolved liquid acetone (2-4\%). Exposure to humidified synthetic air ( $60 \%$ r.h.; $300 \mathrm{ml} / \mathrm{min}$ ) has almost no effect on the living cells as well as on the signal intensity of consecutive acetone exposure. Feasibility of the in vitro sensor system for sequential exposures to synthetic air and acetone was shown. The results obtained so far, show the sensitivity of the combination between an in vitro exposure set-up and a sensor system and suggest, that this in vitro sensor system will allow extended further work to other toxic and non-toxic VOCs.

\section{References}

Abdelghani, A., Abdelghani-Jacquin, C., Hillebrandt, H., Sackmann, E., 2002. Materials Science and Engineering C 22 (1), 67-72.

ACGIH, 1999. TLVs and BEIs. Threshold Limit Values for Chemical Substances and Physical Agents. Biological Exposure Indices. ACGIH News Letter. Cincinnati, $\mathrm{OH}$.

Arts, J.H.E., Mojet, J., van Gemert, L.J., Emmen, H.H., Lammers, J.H.C.M., Marquart, J., Woutersen, R.A., Feron, V.J., 2002. Critical Reviews in Toxicology 32 (1), 43-66. Aufderheide, M., 2008. Experimental and Toxicologic Pathology 60 (2-3), 163-180. Aufderheide, M., Mohr, U., 1999. Experimental and Toxicologic Pathology 51 (6), 489-490.

Aufderheide, M., Mohr, U., 2000. Experimental and Toxicologic Pathology 52 (3), 265-270.

Bai, S., Yang, T., Abbruscato, T.J., Ahsan, F., 2008. Journal of Pharmaceutical Sciences 97 (3), 1165-1178.

Bakand, S., Hayes, A., Winder, C., Khalil, C., Markovic, B., 2005. Toxicology And Industrial Health 21, 147-157.

Bakand, S., Winder, C., Khalil, C., Hayes, A., 2006. Toxicology Letters 165, 1-10.

Baumann, W.H., Lehmann, M., Schwinde, A., Ehret, R., Brischwein, M., Wolf, B., 1999. Sensors and Actuators B 55 (1), 77-89.
Bitterle, E., Karg, E., Schroeppel, A., Kreyling, W.G., Tippe, A., Ferron, G.A., Schmid, O., Heyder, J., Maier, K.L., Hofer, T., 2006. Chemosphere 65, 1784-1790.

Bohrn, U., Stütz, E., Fleischer, M., Schöning, M.J., Wagner, P., 2010. Procedia Engineering 5, 17-20.

Bohrn, U., Stütz, E., Fleischer, M., Schöning, M.J., Wagner, P., 2011a. Physica Status Solidi (a) 208 (6), 1345-1350.

Bohrn, U., Stütz, E., Fuchs, K., Fleischer, M., Schöning, M.J., Wagner, P., 2011b. Procedia Engineering 25, 1421-1424.

Bolton, D.C., Tarkington, B.K., Zee, Y.C., JW, O., 1982. Environmental Research 27, 466-475.

Costa, C., De Pasquale, R., Silvari, V., Barbaro, M., Catania, S., 2006. Toxicology in Vitro 20 (3), 324-331.

Deschl, U., Vogel, J., Aufderheide, M., 2011. Experimental and Toxicologic Pathology 62 (6), 593-598.

Ehret, R., Baumann, W., Brischwein, M., Schwinde, A., Stegbauer, K., Wolf, B., 1997. Biosensors and Bioelectronics 12 (1), 29-41.

Gminski, R., Tang, T., Mersch-Sundermann, V., 2010. Toxicology Letters 196, 33-41.

Guerrero, R.R., Rounds, D.E., Booher, J., Olson, R.S., J.D., H., 1979. Archives of Environmental Health 34, 407-412.

Hillebrandt, H., Abdelghani, A., Abdelghani-Jacquin, C., Aepfelbacher, M. Sackmann, E., 2001. Applied Physics A 73, 539-546.

Hukkanan, J., Lassila, A., Paivarinta, K., Valanne, S., Sarpo, S., Hakkola, J., Pelkonnen, O., Raunio, H., 2000. American Journal of Respiratory Cell and Molecular Biology 22, 360-366.

Knebel, J.W., Ritter, D., Aufderheide, M., 1998. Toxicology Letters 96-97, 1-11.

Kubisch, R., Bohrn, U., Fleischer, M., Stütz, E., 2012. Sensors 12 (3), 3370-3393.

Mosmann, T., 1983. Journal of Immunological Methods 65 (1-2), 55-63.

Pariselli, F., Sacco, M.G., Rembges, D., 2009. Experimental and Toxicologic Pathology : Official Journal of the Gesellschaft fur Toxikologische Pathologie 61, 33-39.

Persoz, C., Leleu, C., Achard, S., Fasseu, M., Menotti, J., Meneceur, P., Momas, I. Derouin, F., Seta, N., 2011. Toxicology Letters 207 (1), 53-59.

Ritter, D., Knebel, J.W., Aufderheide, M., 2001. Experimental and Toxicologic Pathology 53 (5), 373-386.

Röker, S., Aufderheide, M., Möhle, N., Krischenowski, O., 2010. Toxicology Letters 196, S150.

Sasaki, T., Kawai, K., Saijo-Kurita, K., Ohno, T., 1992. Toxicology in Vitro 6 (5), 451-457.

Tsai, J.C., Sheu, H.M., Hung, P.L., Cheng, C.L., 2001. Journal of Pharmaceutical Sciences 90 (9), 1242-1254.

Tsukue, N., Okumura, H., Ito, T., Sugiyama, G., Nakajima, T., 2010. Toxicology in Vitro 24, 363-369.

VOC Solvents Emissions Directive, 1999. Council Directive 1999/13/EC

Wengst, A., Reichl, S., 2010. European Journal of Pharmaceutics and Biopharmaceutics : Official Journal of Arbeitsgemeinschaft fur Pharmazeutische Verfahrenstechnik eV 74, 290-297.

Wolz, L., Krause, G., Scherer, G., Aufderheide, M., Mohr, U., 2002. Food and Chemical Toxicology : An International Journal Published for the British Industrial Biological Research Association 40 (6), 845-850. 